\title{
Tantalum Oxide Coatings as Candidate Environmental Barriers
}

\author{
Monica Moldovan, C.M. Weyant, D. Lynn Johnson, and K.T. Faber
}

(Submitted 17 July 2003; in revised form 17 August 2003)

\begin{abstract}
Tantalum (Ta) oxide, due to its high-temperature capabilities and thermal expansion coefficient similar to silicon nitride, is a promising candidate for environmental barriers for silicon ( $\mathrm{Si}$ ) nitride-based ceramics. This paper focuses on the development of plasma-sprayed Ta oxide as an environmental barrier coating for silicon nitride. Using a D-optimal design of experiments, plasma-spray processing variables were optimized to maximize coating density. The effect of processing variables on coating thickness was also determined. $X$-ray diffraction (XRD) was use to ascertain that the as-sprayed coatings were comprised of $\alpha$ - and $\beta$ - $\mathrm{Ta}_{2} \mathrm{O}_{5}$, but were fully converted to $\beta-\mathrm{Ta}_{2} \mathrm{O}_{5}$ after a $1200{ }^{\circ} \mathrm{C}$ heat treatment. Grain growth of the $\mathrm{Ta}_{2} \mathrm{O}_{5}$ followed a time dependence of $t^{0.2}$ at $1200{ }^{\circ} \mathrm{C}$.
\end{abstract}

Key words environmental barrier coating, plasma spray, tantalum oxide

\section{Introduction}

Silicon (Si)-based ceramics for structural components in power generation applications suffer degradation at high temperatures, pressures, water vapor contents, and gas velocities. This degradation takes the form of the recession of the protective silicon dioxide coating formed via oxidation of the silicon nitride or carbide. ${ }^{[1-5]}$ The oxide degrades primarily by evaporation of volatile silicon hydroxides. ${ }^{[1-4,6,7]}$ Hence, an environmental barrier coating (EBC) is required to protect the silicon dioxide and achieve the necessary lifetime for components in power generation applications.

Requirements for any protective coating that must undergo thermal cycling include chemical stability in the hightemperature environment against oxygen, water vapor, and other impurities. EBCs further require chemical and thermal compatibility with the substrate and microstructural stability over the expected lifetime of the system (e.g., $>10000 \mathrm{~h}$ for turbine systems). ${ }^{[6]}$ A final requirement is ease of processing. One candidate that meets some of these requirements for $\mathrm{Si}_{3} \mathrm{~N}_{4}$-based systems is $\mathrm{Ta}_{2} \mathrm{O}_{5}$. Honeywell International (Morristown, NJ) was first to develop plasma-sprayed $\mathrm{Ta}_{2} \mathrm{O}_{5}$ as an environmental barrier for $\mathrm{Si}_{3} \mathrm{~N}_{4} \cdot{ }^{[8]}$

Ta oxide is a high melting point oxide (m.p. $\left.=1800^{\circ} \mathrm{C}\right)$ with a coefficient of thermal expansion (CTE) well-matched to AS800, a commercially available Si nitride from Honeywell, Inc. For Ta oxide, a CTE of $3.00 \times 10^{-6}{ }^{\circ} \mathrm{C}^{-1}$ has been measured by $\mathrm{x}$-ray diffraction (XRD) over an unreported temperature range. ${ }^{[9]}$ Dilatometery results provide expansion values of $\beta-\mathrm{Ta}_{2} \mathrm{O}_{5}$ of $2.9 \times 10^{-6}{ }^{\circ} \mathrm{C}^{-1}$ for the temperature range from room temperature (RT) to $550{ }^{\circ} \mathrm{C}$, and $4.0 \times 10^{-6}{ }^{\circ} \mathrm{C}^{-1}$ from 550 to $1200{ }^{\circ} \mathrm{C} .{ }^{[10]}$ In comparison, AS 800 has CTE values of

Monica Moldovan, C.M. Weyant, D. Lynn Johnson, and K.T. Faber, Department of Materials Science and Engineering, Robert R. McCormick School of Engineering and Applied Science, Northwestern University, Evanston, IL 60208-3108. Contact e-mail: k-faber@ northwestern.edu.
$2.3 \times 10^{-6}{ }^{\circ} \mathrm{C}^{-1}$ from RT to $240{ }^{\circ} \mathrm{C}, 3.8 \times 10^{-6}{ }^{\circ} \mathrm{C}^{-1}$ from 240 to $775^{\circ} \mathrm{C}$, and $5.6 \times 10^{-6}{ }^{\circ} \mathrm{C}^{-1}$ from 775 to $1000^{\circ} \mathrm{C}$, as estimated from dilatometry measurements. ${ }^{[11]}{ }^{1}$ These values suggest that the coating should be in slight compression upon cooling.

On heating, $\mathrm{Ta}_{2} \mathrm{O}_{5}$ undergoes a phase transformation at $1360^{\circ} \mathrm{C}$ from $\beta-\mathrm{Ta}_{2} \mathrm{O}_{5}$ (orthorhombic) to $\alpha-\mathrm{Ta}_{2} \mathrm{O}_{5}$ (tetragonal). The transformation ideally should be avoided since it involves a large volume change. ${ }^{[12]}$ Another important reason why the transformation should be avoided is that the high-temperature $\alpha$-phase has been shown to be an intrinsic fast ion conductor, clearly undesirable for an environmental barrier. ${ }^{[13]}$ Therefore, production of the low temperature, orthorhombic $\beta$ phase of Ta oxide is preferred. A Ta oxide coating, which undergoes a polymorphic transformation during thermal cycling, could result in spallation due to phase-transformation-induced stresses.

Much of the early work on the processing of $\mathrm{Ta}_{2} \mathrm{O}_{5}$ has involved chemical vapor deposition. ${ }^{[9,14-19]}$ Little work has been accomplished on plasma-spraying of such coatings. We describe here an optimization process to maximize coating density and thickness for $\mathrm{Ta}_{2} \mathrm{O}_{5}$ coatings produced via plasma spray using designed experiments. Further, we examine their phase composition, with specific attention to the $\alpha / \beta$ polymorphs, and microstructural stability through heat treatments at $1200{ }^{\circ} \mathrm{C}$.

\section{Experimental Procedures}

\subsection{Plasma Spraying}

Ta oxide powder (First Reaction P3428, Hampton Falls, NH) was plasma-sprayed on AS800 silicon nitride substrates (Honeywell, Ceramic Components, Torrane, CA). The powder with reported particle size $<40 \mu \mathrm{m}$, shows agglomerates of $20-40 \mu \mathrm{m}$ formed by micron-sized particles. An A-3000 Plasma-Technik control system with an F4 gun (Sulzer Metco, Westburg, NY), mounted on a seven-axis ASEA Brown Boveri IRB 2000 robot (Zurich, Switzerland) was used to spray the coatings. The robot was programmed to scan across and down the substrate for 30

\footnotetext{
${ }^{1}$ Note, average CTE reported by Honeywell $=3.9 \times 10^{-6}{ }^{\circ} \mathrm{C}^{-1}$ for $T=20$ to $1000{ }^{\circ} \mathrm{C}$.
} 


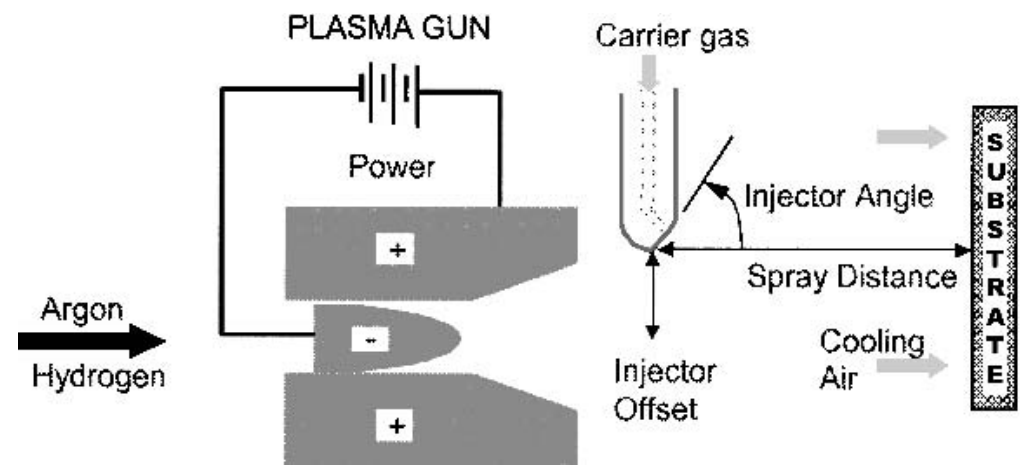

Fig. 1 Illustration of parameters varied in designed experiments for plasma spraying of $\mathrm{Ta}_{2} \mathrm{O}_{5}$

cycles. The small particle plasma spray (SPPS) process was used for spraying all of the samples in the first round of the optimization. ${ }^{[20]}$ SPPS is a modified air plasma spray system that incorporates a powder injector with a narrower elliptical powder feed channel and a beveled tip, where the injector exit is angled with respect to the plasma centerline, shown in Fig. 1. This allows powders to be entrained in the outer isotherms of the plasma stream and efficiently be deposited onto the substrate. ${ }^{[21]}$ SPPS was developed to increase coating quality, in particular density, through the use of smaller powders with particles less than $10 \mu \mathrm{m}$. For the second round of experiments both a straight (zero angle) and the SPPS injector were used.

All the substrates $(1 \times 1 \times 0.5 \mathrm{in}$. $)$ were cleaned ultrasonically for $5 \mathrm{~min}$ in propanol prior to spraying. The substrate was held between a ceramic plate with a circular opening on the front and a back plate containing heating elements. After the substrate was preheated, thermal spraying would commence. A thermocouple was used to measure the temperature on the back of the substrate.

\subsection{Process Optimization}

Excluding characteristics of the powder and substrate, there are 26 variables in the plasma spray process, which include those associated with plasma stream formation, powder feeding, and deposition. ${ }^{[22]}$ Another six variables are associated with the substrate and four with the powder. It would be both tedious and uneconomical to conduct experiments in the traditional wayby varying one parameter at a time while others are held constant. Instead, a statistical design of experiments can be used in which a set of experiments is run that affords the determination of the effect of each variable and the effects of the interactions between or among variables with a minimum number of experiments. Due to its inherent efficiency, and since one of the factors was to be tested at three levels, a D-optimal method is used for the studies reported here. ${ }^{[23,24]}$

For the first round of design of experiments, seven parameters were varied at two levels: injector angle, plasma power, total gas flow, percent hydrogen in plasma gas, spray distance, carrier gas flow, and air cooling. Another parameter, the offset of the injector, was varied at three levels. These variables were chosen based upon historical knowledge of the plasma spray process. The variable settings are shown in Table 1. The disc speed feeding the powder was held at a constant speed at $0.3 \mathrm{rpm}$ and the rastering speed of the torch across the substrate was 350
Table 1 Parameters Used in the First Round of Design of Experiments

\begin{tabular}{ll}
\hline Parameter & \multicolumn{1}{c}{ Value } \\
\hline Injector offset (O) & $6,7,8 \mathrm{~mm}$ \\
Injector angle (A) & $30^{\circ}, 50^{\circ}$ \\
Plasma gun power (P) & $30,40 \mathrm{~kW}$ \\
Total plasma gas flow (Ar $\left.+\mathrm{H}_{2}\right)(\mathrm{TGF})$ & $40,50 \mathrm{slm}$ \\
Percent hydrogen in plasma gas $(\% \mathrm{H})$ & $20 \%, 25 \%$ \\
Spraying distance (D) & $9,11 \mathrm{~cm}$ \\
Carrier gas flow (Ar) (CF) & $5,8 \mathrm{slm}$ \\
Air cool (C) & on, off \\
\hline
\end{tabular}

$\mathrm{mm} / \mathrm{s}$. Each substrate was scanned 30 times with each scan consisting of horizontal passes across the substrate with a $3 \mathrm{~mm}$ drop between each pass. The experiments were designed using a Doptimal based computer program. ${ }^{[25]}$ The design of experiments resulted in a set of 20 trials, instead of a possible 384 for a full factorial set.

The second round of designed experiments was based on the results of the first round and included six parameters with a total of 16 trials (versus 96 for a full factorial set). Three of the parameters varied in the first round of experiments were held constant at their optimized values: plasma gun power at $40 \mathrm{~kW}$, total plasma gas flow at $44 \mathrm{slm}$, percent hydrogen in plasma gas at $25 \%$. Values higher than these would lead to a rapid degradation of the plasma electrodes. Air jets, which blow cool air on the sample surface during spraying, did not influence the model in the first round, but it was decided to have the air on for the second round to prevent the substrate from overheating. The other four parameters from the first round (injector angle, injector offset, carrier gas flow, and spraying distance) were varied at two levels, with new values being chosen based on the first optimization results. Two additional parameters were varied during the second round: powder feeder disc speed at two levels, and robot scan rate at three levels. The parameter settings for the second round are shown in Table 2.

\subsection{Coating Characterization}

The coated AS- 800 samples were sectioned and polished for microscopic examination. To elucidate the grain structure, the materials required thermal etching at $1200^{\circ} \mathrm{C}$ for $24 \mathrm{~min}$. Scanning electron microscopy (SEM) was used to examine thickness 
and microstructure of the coatings. Phase analysis of optimized, as-sprayed and thermally treated coatings was conducted using high-brilliance x-ray beams from synchrotron radiation at the Advanced Photon Source at Argonne National Laboratory. ${ }^{[12]}$ Optimized coatings on substrates were heat treated in air at $1200^{\circ} \mathrm{C}$ for various times to establish grain growth kinetics and phase evolution of $\mathrm{Ta}_{2} \mathrm{O}_{5}$ plasma-sprayed coatings.

\section{Results and Discussion}

For the 20 samples sprayed during the first round of optimization, the thickness varied between 20 and $120 \mu \mathrm{m}$, and porosity between $1.5 \%$ and $9 \%$ as determined by quantitative stereology. The results of the multiple regression analysis indicate that high power, high gas flow, high $\% \mathrm{H}_{2}$, small spraying distance,

Table 2 Parameters Used in the Second Round of Design of Experiments

\begin{tabular}{ll}
\hline Parameter & \multicolumn{1}{c}{ Value } \\
\hline Injector angle (A) & $0^{\circ}, 30^{\circ}$ \\
Injector offset (O) & $5,7 \mathrm{~mm}$ \\
Carrier gas flow (CF) & $3,5 \mathrm{slm}$ \\
Spraying distance (D) & $7,9 \mathrm{~cm}$ \\
Powder feeder disc speed (DS) & $0.2,0.4 \mathrm{rpm}$ \\
Robot scan rate (R) & $175,350,525 \mathrm{~mm} / \mathrm{min}$ \\
\hline
\end{tabular}

Table 3 Optimized Spraying Conditions After Second Round of Design Experiments

\begin{tabular}{ll}
\hline Parameter & \multicolumn{1}{c}{ Value } \\
\hline Robot scan rate (R) & $315 \mathrm{~mm} / \mathrm{min}$ \\
Injector angle (A) & $0^{\circ}$ \\
Injector offset (O) & $5 \mathrm{~mm}$ \\
Carrier gas flow (CF) & $3 \mathrm{slm}$ \\
Power feeder disc speed (DS) & $0.4 \mathrm{rpm}$ \\
Plasma gun power (P) & $40 \mathrm{~kW}$ \\
Total gas flow (TF) & $44 \mathrm{slm}$ \\
Percent hydrogen in plasma gas $(\% \mathrm{H})$ & $25 \%$ \\
\hline
\end{tabular}

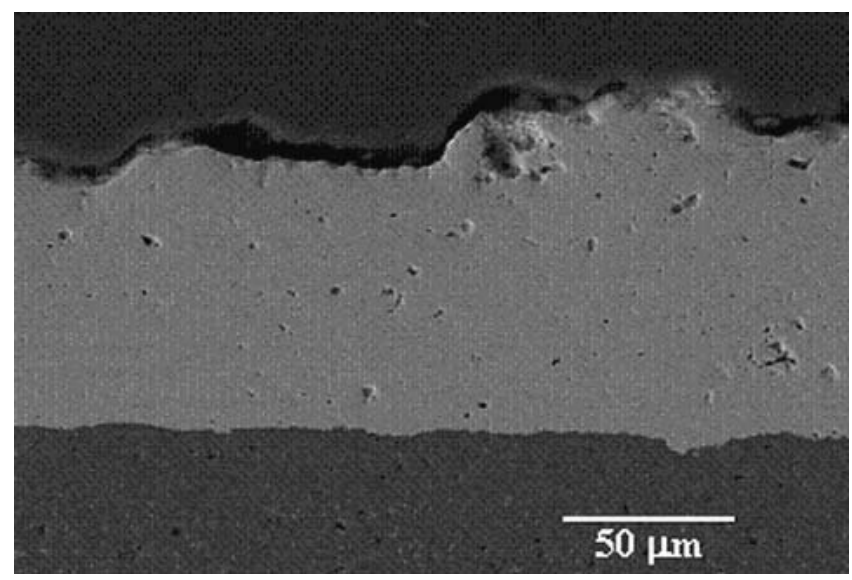

Fig. 2 Scanning electron micrograph of optimized $\mathrm{Ta}_{2} \mathrm{O}_{5}$ coating demonstrating low porosity and adequate thickness and small carrier gas flow are necessary for creating thicker coatings. The offset and angle of the injector were coupled such that either small offset and small angle or high offset and high angle are needed. On the other hand, small offset, small angle, high power, high percent of $\mathrm{H}_{2}$, small distance, minimizes the porosity. Thus, to have both high thickness and low porosity, the parameters should be as follows: small offset, small injector angle, high power, high gas flow, high percent of $\mathrm{H}_{2}$, small spraying distance, and small carrier gas flow.

For the second round of experiments, the thickness varied between 25 and $195 \mu \mathrm{m}$ and the porosity between $1.9 \%$ and $5.7 \%$. However, the large variation in thickness is due to the fact that one of the parameters was the robot scan rate. It is expected that a high rastering speed will produce a thinner coating com-

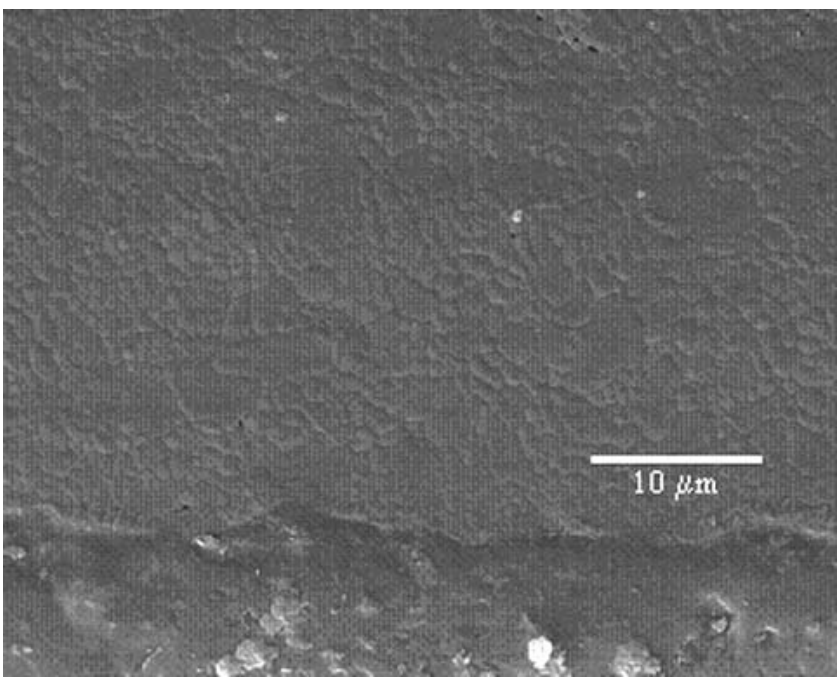

Fig. 3 Scanning electron micrograph of optimized $\mathrm{Ta}_{2} \mathrm{O}_{5}$ thermally etched at $1200^{\circ} \mathrm{C}$ in air for $24 \mathrm{~min}$

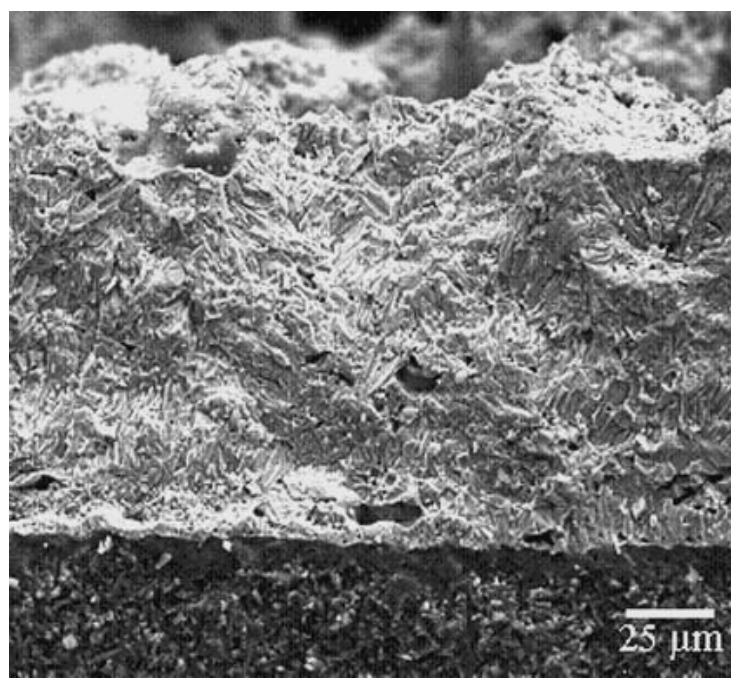

Fig. 4 Fracture surface of an as-sprayed, optimized $\mathrm{Ta}_{2} \mathrm{O}_{3}$ coating on AS800. Note the columnar microstructure typical of plasma-sprayed coatings 
pared with a small speed. This parameter was introduced only to optimize the density.

Multiple regression analysis of the data for thickness $T$ and porosity $P$ yielded the following models:

$$
\begin{aligned}
& \log _{10}(T)=3.48-5.09 \times 10^{-3} \mathrm{R}+1.55 \times 10^{-6} \mathrm{R}^{2}-0.136 \mathrm{O} \\
& \quad-0.0467 \mathrm{D}+1.11 \mathrm{DS}+3.98 \times 10^{-4} \mathrm{R}^{*} \mathrm{O} \\
& \begin{aligned}
1 / P & =-0.340+1.49 \times 10^{-3} \mathrm{R}-2.40 \times 10^{-6} \mathrm{R}^{2}+0.0217 \mathrm{~A} \\
& +0.0950 \mathrm{O}-4.33 \times 10^{-3} \mathrm{~A}^{*} \mathrm{O}
\end{aligned}
\end{aligned}
$$

Note the interaction effects between rate and offset for thickness and angle and offset for porosity (the $\mathrm{R}^{*} \mathrm{O}$ and $\mathrm{A} * \mathrm{O}$ terms).

Since impermeability (low porosity) overrides coating thickness in importance, it was decided to select the parameters such that the porosity would be minimized. These values are shown in Table 3. The predicted means for thickness and porosity computed from these models are $100 \mu \mathrm{m}$ and $2.70 \%$, and the $95 \%$ confidence intervals for the means are $90-113 \mu \mathrm{m}$ for thickness and $2.24 \%$ and $3.41 \%$ for porosity.

Several confirmation runs were completed at the settings shown in Table 3, with results that closely match the values of both thickness and porosity predicted by the above equations. The mean thickness for five runs was $96 \mu \mathrm{m}$, with a $95 \%$ confidence interval for the mean of 86-107 $\mu \mathrm{m}$. The one sample $t$-test indicates one cannot reject the null hypothesis (mean $=100 \mu \mathrm{m}$, $p=0.42$ ). The average porosity for seven specimens was $2.76 \%$, with a $95 \%$ confidence interval for the mean of $1.7 \%$ to $3.8 \%$. Again, the one-sample $t$-test shows one cannot reject the null hypothesis (mean $=2.70 \%, p=0.90)$. Figure 2 shows an optimized coating that has an average thickness of $85 \mu \mathrm{m}$ and approximate porosity of $1.5 \%$ (the smallest value found), as measured by stereological methods.

Thermal etching at $1200^{\circ} \mathrm{C}$ for $24 \mathrm{~min}$ reveals the grain structure, which is not typical for a plasma spray coating. ${ }^{[26]}$ Instead of the typical lamellar microstructure, equiaxed grains, with a bimodal distribution of grain sizes are observed, more reminiscent of a sintered microstructure, as shown in Fig. 3. A first hypothesis was that the resultant microstructure is due to recrystallization during spraying. To verify this hypothesis, a sample was sprayed without preheating the substrate. The same equiaxed microstructure was observed after thermal etching. This would suggest that the resultant microstructures might be influenced by the thermal etching process.

To confirm this, as-sprayed coatings were fractured and examined by SEM. The as-sprayed coating fracture surface is more indicative of plasma-sprayed microstructures. Figure 4 shows regions that clearly represent lamellar microstructures and interlamellar pores. Also seen are columnar grains typical of the solidification process during thermal spraying, although transmission electron microscopy in other plasma-sprayed systems demonstrates that the columnar grains are actually multigrain columns. ${ }^{[27,28]}$ This is consistent with the thermally etched microstructures in this study, shown in Fig. 3.

XRD patterns for the as-sprayed coating and a coating exposed at $1200{ }^{\circ} \mathrm{C}$ in air for $72 \mathrm{~h}$ are shown in Fig. 5. The assprayed coating contains the non-equilibrium high temperature $\alpha$-phase, which is undesirable. Upon thermal treatment, the $\alpha$-phase undergoes a crystallographic transformation resulting in a homogeneous coating containing only the low temperature $\beta$ phase of tantalum oxide.

Thermal stability of these coatings is important, since they are designed to be used at high temperature. A study of grain growth was performed at $1200^{\circ} \mathrm{C}$ in ambient air, and the results are shown in Fig. 6 . The data represent the mean grain size with error bars representing one standard deviation from the mean. Theoretically, grain growth with time follows the relation ${ }^{[29]}$ :

$d^{n}-d_{0}^{n}=(2 k) t$

where $d$ and $d_{0}$ are the grain diameters at time zero and $t$, respectively, and $\mathrm{k}$ is a constant, which includes the grain boundary

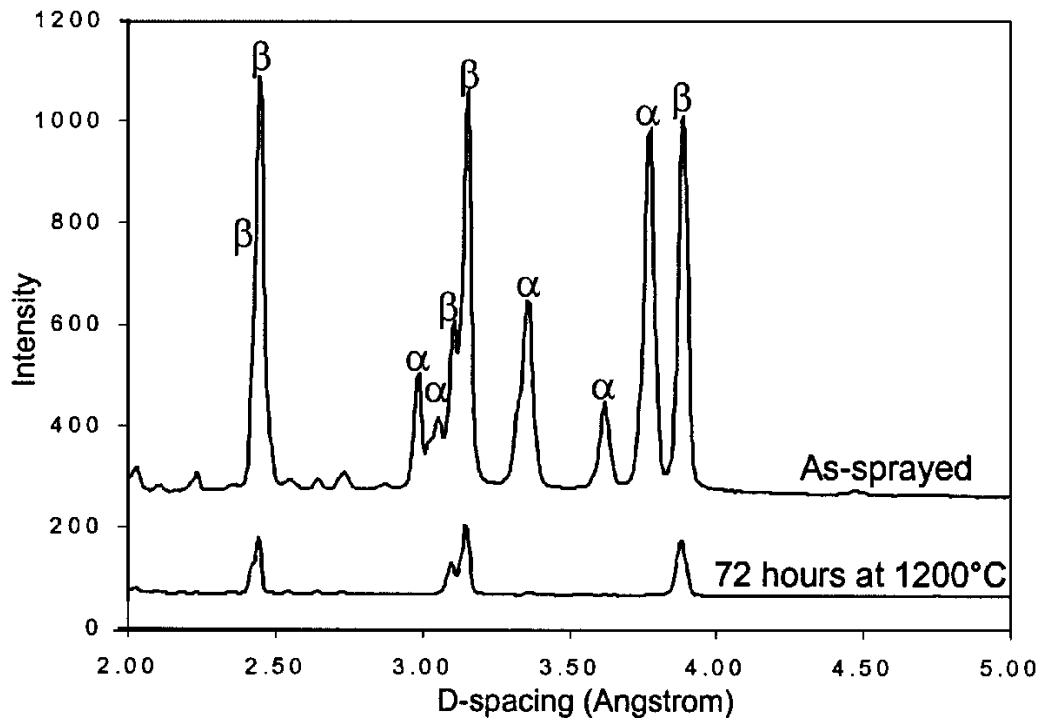

Fig. 5 X-ray diffraction pattern of optimized, as-sprayed coating and thermally treated coating with $\alpha$ and $\beta$ phase peaks labeled showing the presence of $\alpha$-phase in the non-equilibrium as-sprayed coating. 


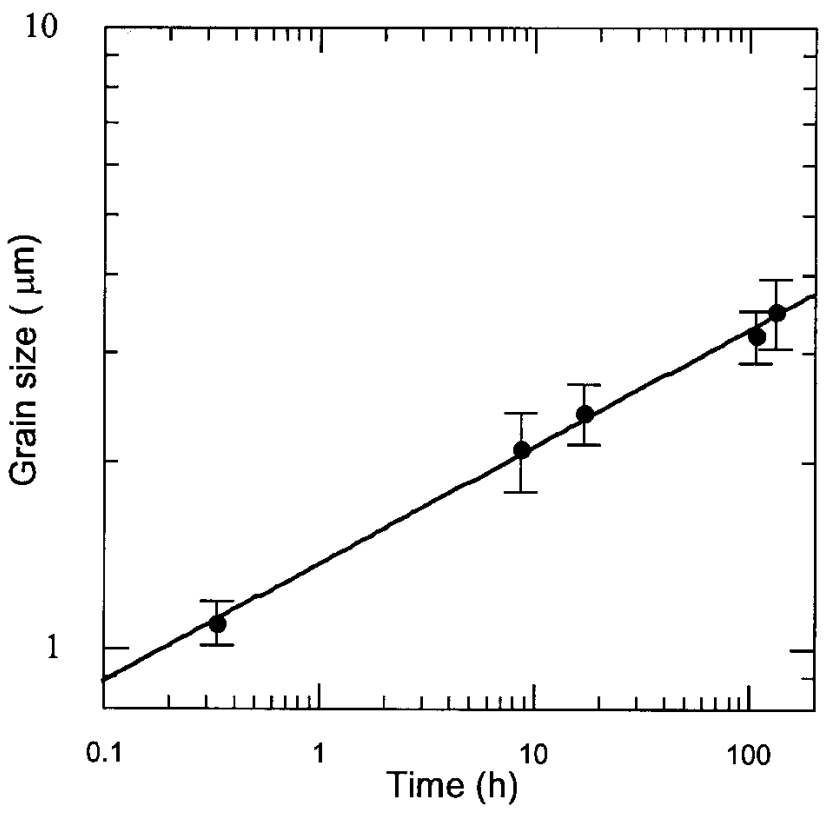

Fig. 6 Grain size as a function of heat-treatment time at $1200{ }^{\circ} \mathrm{C}$ for $\mathrm{Ta}_{2} \mathrm{O}_{5}$ coatings established from polished and thermally etched surfaces; error bars represent one standard error.

mobility. Experimentally it is found that the slope of the $\log d$ versus $\log t$ curve in Fig. 6 is approximately 0.2. This result is consistent with the grain growth exponents for most ceramics, which fall between 0.1 and $0.5 .^{[30]}$ Extrapolating these values to desired lifetimes $(10000 \mathrm{~h})$ suggests that the average grain size would increase to approximately $9 \mu \mathrm{m}$. As the coefficients of thermal expansion of $\mathrm{Ta}_{2} \mathrm{O}_{5}$ are highly anisotropic (see Ref 9, for example), any significant increase in grain size may lead to spontaneous microcracking on cooling. ${ }^{[31]}$ Microcracking may lead to spallation of the coating, but this has yet to be established.

\section{Summary}

A designed experiment route was used to optimize both thickness and density for $\mathrm{Ta}_{2} \mathrm{O}_{5}$ coatings considered for environmental barrier applications. The as-sprayed coatings were approximately $97-98 \%$ dense and were composed of the lowtemperature polymorph, $\beta-\mathrm{Ta}_{2} \mathrm{O}_{5}$ and some $\alpha-\mathrm{Ta}_{2} \mathrm{O}_{5}$, as established using $\mathrm{x}$-ray diffraction. Upon thermal treatment, the $\alpha$-phase was converted to the low-temperature $\beta-\mathrm{Ta}_{2} \mathrm{O}_{5}$ phase. Grain growth at $1200{ }^{\circ} \mathrm{C}$ followed a time dependence of $t^{0.2}$, typical of many ceramic materials. It has not yet been determined whether these grain growth rates are sufficiently low to afford the necessary microstructural stability for environmental barriers.

\section{Acknowledgments}

This work was supported by the U.S. Department of Energy under the Energy Efficiency Sciences Program under Cooperative Agreement No. DE-FC020-01CH11086-A000. AS800 samples were provided by C-W. Li and J. Guiheen, also under the above contract.

\section{References}

1. J.L. Smialek, R.C. Robinson, E.J. Opila, D.S. Fox, and N.S. Jacobson: "SiC and $\mathrm{Si}_{3} \mathrm{~N}_{4}$ Recession Due to $\mathrm{SiO}_{2}$ scale Volatility Under Combustor Conditions," Adv. Composite Mater., 1999, 8(1), pp. 33-45.

2. E.J. Opila: "Variation of the Oxidation Rate of Silicon Carbide With Water-Vapor Pressure," J. Am. Ceram. Soc., 1999, 82(3), pp. 625-36.

3. R.C. Robinson, and J.L. Smialek: "SiC Recession Caused by $\mathrm{SiO}_{2}$ Volatility Under Combustion Conditions: I, Experimental Results and Empirical Model," J. Am. Ceram. Soc., 1999, 82(7), pp. 1817-25.

4. E.J. Opila, J.L. Smialek, R.C. Robinson, D.S. Fox, and N.S. Jacobson: "SiC Recession Caused by $\mathrm{SiO}_{2}$ Volatility Under Combustion Conditions: II, Thermodynamics and Gaseous-Diffusion Model," J. Am. Ceram. Soc., 1999, 82(7), pp. 1826-34.

5. K.L. More, P.F. Tortorelli, M.K. Ferber, and J.R. Keiser: "Observations of Accelerated Silicon Carbide Recession by Oxidation at High WaterVapor Pressures," J. Am. Ceram. Soc., 2000, 83(1), pp. 211-13.

6. K.N. Lee: "Current Status of Environmental Barrier Coatings for SiBased Ceramics," Surf. Coat. Technol., 2000, 133-34, pp. 1-7.

7. H. Klemm: "Corrosion of Silicon Nitride Materials in Gas Turbine Environment," J. Euro. Ceram. Soc., 2002, 78(14-15), pp. 2735-40.

8. C-W. Li, D. Raybould, and L.A. Xue: Environmental and Thermal Barrier Coating for Ceramic Components, U.S. Patent Application 2002/ 0136835 A1, September 26, 2002.

9. Y.W. Bae, W.L. Lee, and D.P. Stinton: "Effects of Temperature and Reagent Concentration on the Morphology of Chemically Vapor Deposited $\beta-\mathrm{Ta}_{2} \mathrm{O}_{5}$," J. Am. Ceram. Soc., 1995, 78(5), pp. 1297-1300.

10. Y.S. Touloukian, R.K. Kirby, R.E. Taylor, and T.Y.R. Lee: Thermal Expansion, Nonmetallic Solids, IFI/ Plenum, New York, 1977, pp. 37475.

11. Honeywell Inc. Sales Literature via J. Guiheen.

12. JCPDS-International Centre for Diffraction Data, Newton Square, PA, Files 19-1300 $\left(\alpha-\mathrm{Ta}_{2} \mathrm{O}_{5}\right)$ and 79-1375 $\left(\beta-\mathrm{Ta}_{2} \mathrm{O}_{5}\right) 2001$

13. G.M. Choi, H.L. Tuller, and J.S. Haggerty: “ $\alpha-\mathrm{Ta}_{2} \mathrm{O}_{5}-\mathrm{An}$ Intrinsic Fast Oxygen Conductor," J. Electrochem. Soc., 1989, 136(3) pp. 835-38.

14. D.J. Peacock: "Vapor Deposition of Thin Films of Tantalum Oxide," Electochem. Technol., 1966, 4(7-8), pp. 443-44.

15. C.C. Wang, K.H. Zaininger, and M.T. Duffy: "Vapor Deposition and Characterization of Metal Oxide Thin Films for Electronic Applications," RCA Rev., 1970, 31(4), pp. 728-41.

16. T. Takahashu and H. Itoh: "Formation of Tantalum Oxide by Chemical Vapor-Deposition,” J. Less Common Met., 1972, 38, pp. 211-19.

17. W.H. Knausenberger and R.N. Tauber: "Selected Properties of Pyrolytic $\mathrm{Ta}_{2} \mathrm{O}_{5}$ Films," J. Electrochem. Soc., 1973, 120(7), pp. 927-31.

18. C.H. An and K. Sugimoto: "In Situ Ellipsometric Analysis of the Formation Process of $\mathrm{Ta}_{2} \mathrm{O}_{5}$ Thin Films in MOCVD," J. Electrochem. Soc., 1990, 123(10), pp. 1570-73.

19. D. Graham and D.P. Stinton: "Development of Tantalum Pentoxide Coatings by Chemical Vapor Deposition," J. Am. Ceram. Soc., 1994, 77(9), pp. 2298-304.

20. T.F. Bernecki and D.R. Marron: Small Particle Plasma Spray Apparatus, Methods, and Coated Articles, U.S. Patent 5,744,777, April 28, 1998 and U.S. Patent 5,858,470, Jan. 12, 1999.

21. Y.J. Su, T.F. Bernecki, and K.T. Faber: "In-Situ Characterization of Small-Particle Plasma-Sprayed Powders," J. Thermal Spray Tech., 2002, 11(1) pp. 52-61.

22. R.W. Smith: Thermal Spray Technology, B. Willis, ed., ASM International, Materials Park, OH, 1992, pp. 1-66.

23. A.C. Atkinson and A.N. Donev: Optimal Experimental Designs, Clarendon Press, Oxford, UK, 1992.

24. F. Pukelsheim: Optimal Design of Experiments, Wiley, New York, 1993.

25. Experimental Design Optimizer, Harold S. Haller \& Company, Cleveland, $\mathrm{OH}$.

26. R. Trice and K.T. Faber: "The Role of Lamellae Morphology on the 
Microstructural Development and Mechanical Properties of SmallParticle Plasma-Sprayed Alumina," J. Am. Ceram. Soc., 2000, 83(5), pp. 889-96.

27. A. de Arellano-López and K.T. Faber, "Microstructural Characterization of Small-Particle Plasma Spray Coatings," J. Am. Ceram. Soc., 1999, 82(8), pp. 2204-08.

28. R. Trice, Y. Su, J. Mawdsley, K.T. Faber, A. de Arellano-López, H. Wang, and W. Porter: "Effect of Heat Treatment on Phase Stability,
Microstructure, and Thermal Conductivity of Plasma-Sprayed YSZ," $J$. Mater. Sci., 2002, 37, pp. 2359-65.

29. M. Hillert: "On Theory of Normal and Abnormal Grain Growth," Acta Metall. 1965, 13(3), pp. 227-38.

30. W.D. Kingery, H.K. Bowen, and D.R. Uhlmann: Introduction to Ceramic Science, 2nd Ed., J. Wiley \& Sons, New York, 1976, pp. 454-55.

31. A.G. Evans: "Microfracture From Thermal-Expansion Anisotropy: I, Single Phase Systems," Acta Metall,. 1978, 26, pp. 1845-53. 